\title{
Viewing "Mathematics for Teaching" as a Form of Applied Mathematics: Implications for the Mathematical Preparation of Teachers
}

\author{
Andreas J. Stylianides and Gabriel J. Stylianides
}

\begin{abstract}
Introduction
The profound implications of teachers' mathematical knowledge for the quality of the learning opportunities that teachers can offer to their students (e.g., [2]) justifies, at least in part, the growing research focus on teachers' mathematical knowledge. This research has given rise to the notion of Mathematics for Teaching (MfT) [3], [4], which describes the body of mathematics that is important for teachers to know in order to be able to successfully manage the mathematical demands of their professional practice, i.e., teaching mathematics to children. This is contrasted, for example, with the mathematics that is important for other professionals such as engineers and physicists
\end{abstract}

Andreas Stylianides lectures mathematics education at the University of Cambridge, UK. His email address is as899@cam.ac.uk.

Gabriel Stylianides lectures mathematics education at the University of Oxford, UK. His email address is gabrie1. stylianides@education.ox.ac.uk.

The present article draws on an article that we published in a general education research journal [1]. Parts of that article are reused herein with permission (license number: 2963601258532). The research underpinning the articles was supported by funds from the Spencer Foundation (grant numbers 200700100 and 200800104). We thank James Sandefur and three reviewers for their useful comments on earlier versions of the present article.

DOI: http://dx.doi.org/10.1090/noti1087 whose work also imposes specific mathematical demands. Of course there is overlap between the mathematics that is important to different workplaces. Yet there are also certain mathematical ideas or ways of knowing and knowing how to use these ideas that are more relevant to one workplace than to another.

In this article we discuss a conceptualization whereby MfT is thought of as a form of applied mathematics, and we probe the implications of this conceptualization for the mathematical preparation of teachers. We also relate our discussion of MfT as a form of applied mathematics to how Hyman Bass and Zalman Usiskin used the notion of "applied mathematics" to think about mathematics education or the mathematical preparation of teachers.

\section{Exemplifying Knowledge of Mathematics for Teaching}

We begin with a classroom scenario that we use to exemplify elements of knowledge of MfT in the particular domain of proof.

\section{Classroom scenario:}

A seventh-grade class was reviewing methods for finding a fraction between any two given fractions that are not equivalent and can be located on the positive part of the number line. At one point during the lesson, a student in the class, Mark, announced 
proudly his discovery of the following general method for finding a fraction between any two such fractions:

To find the numerator of a fraction that lies between any two given fractions on the number line, you simply add the numerators of the two given fractions. To find the denominator, you simply add their denominators.

Mark illustrated his method with an example, which is shown in Figure 1. He also clarified that his method gives one out of many possible fractions between any two given (positive and nonequivalent) fractions.

The other students in the class were amazed with the method, tested it with lots of examples, and saw that it worked in every case they checked. Then many students became convinced that Mark's method works for any pair of fractions. One of them, Jane, asked the teacher:

Can we use this method every time we need to find a fraction between two given positive fractions?

The teacher found herself in a difficult situation: this was the first time that she had seen the method and was not sure how to respond to Jane's question.

A major mathematical issue that arose for the teacher in the scenario was whether it would be mathematically appropriate for the students in the class to use Mark's method to find a fraction between any two given positive and nonequivalent fractions. The teacher was seeing this method, which draws on the mediant property of positive fractions, for the first time. The teacher's mathematical knowledge could shape the course of action she would follow in the classroom scenario, which in turn would influence students' opportunities to learn mathematics. Consider, for example, the following two possibilities that originate from two different elements of knowledge that the teacher could possess.

Possibility 1:

A possible element of the teacher's mathematical knowledge (misconception): If a general method is found to work for many different cases (a proper subset of all possible cases), then the method can be accepted as correct.

$\rightarrow$ Course of action: The teacher considers Mark's method to be correct and says to Jane and the rest of the class that they can use the method every time they need to find a fraction between two given positive and nonequivalent fractions. $\rightarrow$ Students' opportunities to learn mathematics: The students add a new method to their "toolkit" (which happens to be correct), but they are led to develop or continue to hold the same misconception as their teacher.

Possibility 2:

An alternative possible element of the teacher's mathematical knowledge (sound conception): Unless a general method is proved to work for all possible cases, the method cannot be accepted as correct.

$\rightarrow$ Course of action: The teacher says to Jane and the rest of the class that even though Mark's method worked in all the cases they checked, there are infinitely many pairs of fractions and so the examination of some of these pairs offers no guarantee that the method will work for all possible cases. Also, the teacher invites the students to join her in thinking more about the method to see whether they can prove that the method works for all possible cases.

$\rightarrow$ Students' opportunities to learn mathematics: The students are exposed to the mathematically sound idea that the confirming evidence offered by some cases is not enough to establish the correctness of a general method. Also, the students engage with their teacher in an exploration that can potentially lead to the development of a proof for the method. If a proof is developed, the students can add the method to their "toolkit"; otherwise, the class would treat the method as a conjecture.

Prior research (e.g., [5], [6]) shows that many teachers have the misconception described in possibility 1 , namely, that examination of a proper subset of all the possible cases constitutes a proof of a general method. Prior research shows further that many students of all levels of education have the same misconception (see [7] for a review of some of this research). Possibility 1 illustrates how a teacher's misconception can generate or reinforce the same misconception among students, while possibility 2 illustrates how a sound conception could allow a teacher to offer to students learning opportunities to develop the same sound conception. The sound conception in possibility 2 is "fundamental" [2] in the sense that it can apply to the mathematical work of all students (including young children) and contains the rudiments of more advanced mathematical issues (notably, what counts as evidence in mathematics).

Given the important implications that possession by the teacher of this sound conception could have for students' opportunities to learn 
I begin with two positive fractions, say $\frac{1}{2}$ and $\frac{3}{4}$.

To find a fraction between these two fractions I do the following:

$$
\frac{1+3}{2+4}=\frac{4}{6}
$$

I use the number line to show that my method worked:

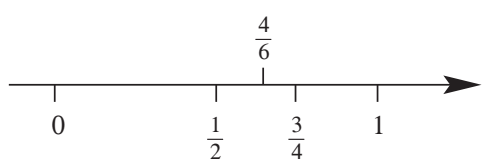

$\frac{4}{6}$ is between $\frac{1}{2}$ and $\frac{3}{4}$.

Figure 1. A student's illustration of a method for finding a fraction between two given positive and nonequivalent fractions.

mathematics, we can consider the conception to be an element of knowledge of MfT [8]. Note that we do not suggest that knowledge of the mediant property of positive fractions should also be an element of knowledge of MfT. Although knowledge of this property would likely help the teacher deal with the particular classroom scenario, it is not the kind of "fundamental" knowledge that could have high currency in the work of mathematics teaching.

Of course the element of mathematical knowledge in possibility 2 is important for effective functioning not only in teaching but also in other workplaces. Thus, this element is not unique to knowledge of MfT. A related element that is more relevant to teaching than to other workplaces that use mathematics is knowledge of an actual proof of Mark's method that would be not only (a) mathematically valid but also (b) pedagogically appropriate for use with seventh-graders. Indeed, a physicist or an engineer would likely be concerned only with the mathematical validity of the proof, while a teacher would have to consider also issues such as students' prior knowledge and whether, for example, an algebraic proof would be accessible to them. Later we will revisit the classroom scenario, and we will discuss different possible proofs that could meet both requirements.

Our previous discussion illustrates the point that a teacher's mathematical knowledge cannot generally function in isolation from pedagogical considerations and, by implication, university mathematics courses for prospective teachers cannot lose sight of the domain of application of the targeted knowledge (i.e., mathematics teaching).
This should not be interpreted as a suggestion to compromise the mathematical focus of mathematics courses for prospective teachers. On the contrary, we are strong believers that the focus in these courses should remain on mathematics. Our interest is in how to best promote prospective teachers' learning of mathematics in these courses, and, in this regard, we suggest that at least part of prospective teachers' learning experiences should be contextualized in pedagogical situations, thereby fostering connections with the domain of application of the intended learning.

\section{Conceptualizing Mathematics for Teaching as a Form of Applied Mathematics}

Hyman Bass and Zalman Usiskin both used the notion of "applied mathematics" in discussing, respectively, "mathematics education" and "teachers' mathematics". Hung-Hsi Wu also discussed relevant ideas, though he used the notion of "mathematical engineering" instead of "applied mathematics". Below we briefly present the views of these researchers and use them to situate our proposal in this article to view MfT as a form of applied mathematics.

Bass [9] suggested that we view mathematics education as a form of applied mathematics: "[Mathematics education] is a domain of professional work that makes fundamental use of highly specialized kinds of mathematical knowledge, and in that sense it can... be usefully viewed as a kind of applied mathematics" (p. 418). ${ }^{1} \mathrm{Wu}$ [10] expressed a somewhat similar idea when he argued that "mathematics education is mathematical engineering, in the sense that it is the customization of basic mathematical principles to meet the needs of teachers and students" (p. 1678). In his view, the customization of mathematics needs to happen before the mathematics can be applied in the work of teaching. It seems to us that Wu's notion of engineering relates primarily to curriculum development, whereas Bass's notion of applied mathematics is concerned mainly with the practice of teaching and its mathematical demands.

Zalman Usiskin [11], [12] has also discussed the notion of applied mathematics, but, contrary to Bass [9], he has done so in the context of what he calls "teachers' mathematics". Usiskin [11] discusses eight aspects under "teachers' mathematics": "(a) ways of explaining and representing ideas new to students, (b) alternate definitions and their consequences, (c) why concepts arose and how they

\footnotetext{
${ }^{1}$ Although this quotation is dated 2005, Bass has discussed the idea of viewing mathematics education as a form of applied mathematics in public talks since the 1990s. Wu [10] notes, for example, that Bass lectured on this idea in 1996.
} 
have changed over time, (d) the wide range of applications of the mathematical ideas being taught, (e) alternate ways of approaching problems with and without calculator and computer technology, (f) extensions and generalizations of problems and proofs, (g) how ideas studied in school relate to ideas students may encounter in later mathematics study, and (h) responses to questions that learners have about what they are learning" (p. 3). Although Usiskin's notion of "teachers' mathematics" is certainly not unrelated to the notion of MfT as we described it earlier in this article, the connections between Usiskin's "teachers' mathematics" and pedagogy are mainly curricular and not so much about teaching and its mathematical demands, as is the case in MfT. For example, the list (a)-(h) of aspects of "teachers' mathematics" includes only one item, (h), that specifically refers to teaching.

In thinking about the mathematical preparation of teachers, we were inspired by Bass's use of "applied mathematics". 2 Yet, given that mathematics education in general and the work of mathematics teaching in particular make use of specialized kinds of knowledge from several other fields in addition to mathematics (psychology, sociology, etc.), we propose to use the characterization "form of applied mathematics" in reference to the mathematical component of teachers' work (i.e., MfT) rather than to mathematics education in general, as Bass used it. Traditionally, the term "applied mathematics" has been associated with the use of mathematical knowledge in particular domains of professional work, such as those that relate to engineering and physics. Our use of this term for the domain of professional work that relates to mathematics teaching aims to extend rather than change its traditional meaning.

Our proposal to conceptualize MfT as a form of applied mathematics is partly motivated by the fact that the conceptualization has two important implications for the mathematical preparation of teachers. These implications, which we describe next, are aligned with existing research in this area.

First, the conceptualization implies that the mathematical preparation of teachers should take seriously into account the idea that "there is a specificity to the mathematics that teachers need to know and know how to use" ([13], p. 271) as compared to the mathematics that other professional users of mathematics need to know and know how to use. This point was illustrated earlier when we talked about mathematical knowledge needed to develop a proof of Mark's method that would also be accessible to seventh-graders: knowledge of

\footnotetext{
${ }^{2}$ Only recently did we learn about Usiskin's use of "applied mathematics". We thank the anonymous referee who brought this work to our attention.
}

such a "pedagogically situated" proof would be crucial for the teacher in the classroom scenario but not so much for a physicist or an engineer who may have an interest in the same method.

Second, the conceptualization implies that the mathematical preparation of teachers should aim to "create opportunities for learning subject matter that would enable teachers not only to know, but to learn to use what they know in the varied contexts of [their] practice" ([3], p. 99). In other words, the conceptualization underscores the importance of a "pedagogically functional mathematical knowledge" (ibid., p. 95) which can support teachers to successfully address mathematical issues that arise in their work, such as mathematical evaluation of a novel student method or the generation of a "pedagogically situated" proof, as illustrated in our discussion of the classroom scenario.

To recap, the conceptualization of MfT as a form of applied mathematics necessitates that mathematics courses for prospective teachers design opportunities for prospective teachers to learn and be able to use mathematical knowledge from the perspective of an adult who is specifically preparing to become a teacher of mathematics. But how might such learning opportunities be designed? Next we discuss a special kind of mathematics task that we call Pedagogy-Related mathematics tasks (P-R mathematics tasks), which we used in our courses with prospective teachers to support their learning of MfT. We do not suggest that P-R mathematics tasks are the only or the best kinds of tasks for promoting learning of MfT. Yet, we claim that P-R mathematics tasks can support productive learning opportunities for prospective teachers to develop the mathematical knowledge that they need for their work and that such tasks should not be overlooked in the mathematical preparation of teachers.

\section{Pedagogy-Related Mathematics Tasks: A Vehicle to Promoting Knowledge of Mathematics for Teaching}

In this section we discuss the notion of P-R mathematics tasks as a vehicle to promoting knowledge of MfT. Specifically, we discuss two main features of $\mathrm{P}-\mathrm{R}$ mathematics tasks that collectively distinguish P-R mathematics tasks from other kinds of mathematics tasks.

As an example of a P-R mathematics task, consider the following question in relation to the classroom scenario described earlier:

What would be a mathematically appropriate way in which the teacher could respond to Jane's question about whether the class could use Mark's method every time they had to find a fraction between two given, nonequivalent positive fractions? 


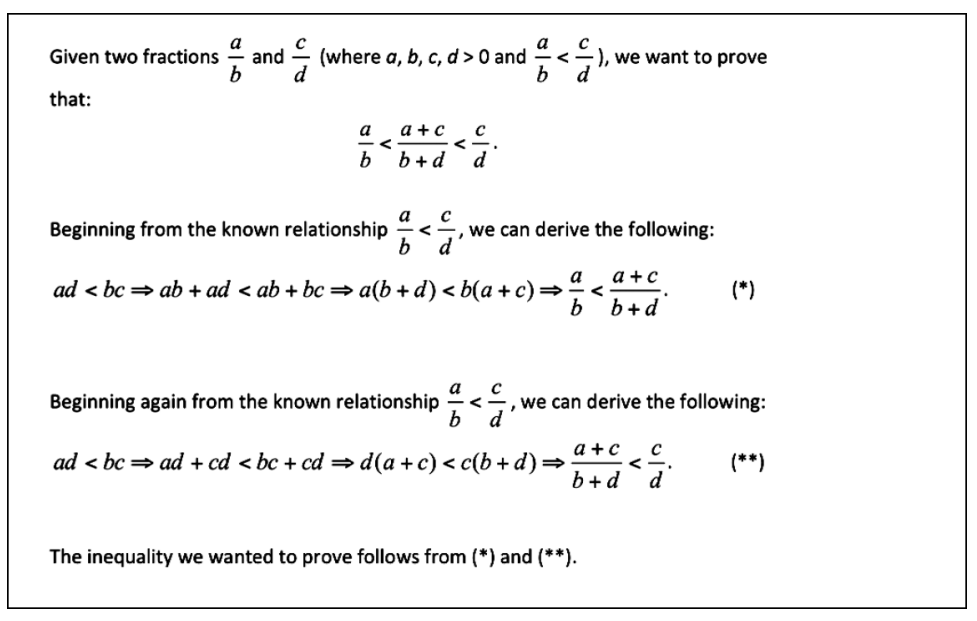

Figure 2. An algebraic proof of a general method for finding a fraction between two given positive and nonequivalent fractions.

We will henceforth refer to this task as the Fractions Task. A solution to the Fractions Task would build on the "course of action" that we discussed earlier under possibility 2, which is the desirable possibility. According to this course of action, the teacher would engage the class in the discussion of a proof that would not only be valid but also accessible to the group of seventh-graders.

\section{Feature 1: A mathematical focus}

$\mathrm{P}-\mathrm{R}$ mathematics tasks have a mathematical focus that relates to one or more mathematical ideas that theory, research, or practice suggested are important for teachers to know. The mathematical focus is intended to engage prospective teachers in mathematical activity. In the Fractions Task, the mathematical focus is the mathematical evaluation of Mark's method, which can be expressed algebraically as follows:

Given two fractions $\frac{a}{b}$ and $\frac{c}{d}$ (where $a, b, c, d>0$ and $\left.\frac{a}{b}<\frac{c}{d}\right), \frac{a}{b}<\frac{a+c}{b+d}<\frac{c}{d}$.

\section{Feature 2: A substantial pedagogical context}

In addition to the mathematical focus, a P-R mathematics task has a substantial pedagogical context that is an integral part of the task and essential for its solution. The pedagogical context situates prospective teachers' mathematical activity in a particular teaching scenario and helps prospective teachers engage with the mathematics from the perspective of a teacher.

In the Fractions Task the pedagogical context describes the teacher's need to formulate a response to Jane's question about whether the class could use Mark's method when asked to find a fraction between two positive and nonequivalent fractions. According to this context, the event happened in a seventh-grade class, which allows the solvers of the task (prospective teachers) to make certain assumptions about what the students in the class might know or be able to understand. Thus a solution to the task must not only satisfy mathematical considerations but also needs to take into account pedagogical considerations. Next we discuss four points related to feature 2 of P-R mathematics tasks.

First, the pedagogical context in which a P-R mathematics task is situated determines to a great extent what counts as an acceptable/appropriate solution to the task, because it provides (or suggests) a set of conditions a possible solution to the task needs to satisfy. In the Fractions Task, for example, an algebraic proof of Mark's method like the one in Figure 2, though mathematically valid, would likely not be within the conceptual reach of students in a seventh-grade class. A proof can only be useful to students if it is understandable to them. It is up to the teacher to decide whether, given students' prior knowledge and any national curricular expectations, it would be sensible to engage the class in the development of a different proof that could be more accessible to students.

A potential proof of the inequality $\frac{a}{b}<\frac{a+c}{b+d}<\frac{c}{d}$ that invokes an argument from physics would likely have stronger explanatory power and be more accessible to students than the algebraic proof. Consider, for example, the distance-time graph in Figure 3, with the fractions $\frac{a}{b}, \frac{c}{d}$, and $\frac{a+c}{b+d}$ representing respectively the following speeds: the constant speed for covering distance $a$ in time $b$, the constant speed for covering an additional distance $c$ in time $d$, and the average speed for covering the entire distance $(a+c)$ in time $(b+d)$. The smaller the fraction the smaller the speed, and so the fact that $\frac{a}{b}$ is smaller than $\frac{c}{d}$ implies that the constant speed for covering distance $a$ is smaller than the constant speed for covering distance $c$; this is illustrated by the smaller slope of OP as compared to the slope of $\mathrm{PQ}$ in the figure. The average speed for covering the entire distance $(a+c)$ in time $(b+d)$ should be: (1) bigger than $\frac{a}{b}$, because, otherwise, a smaller distance than $(a+c)$ would be covered in time $(b+d)$; and (2) smaller than $\frac{c}{d}$, because, otherwise, distance $(a+c)$ would be covered in less time than $(b+d)$. Thus it follows that $\frac{a}{b}<\frac{a+c}{b+d}<\frac{c}{d}$.

Another possible argument for the inequality $\frac{a}{b}<\frac{a+c}{b+d}<\frac{c}{d}$ that could possibly be more accessible to students than the algebraic proof might consider that the fractions $\frac{a}{b}$ and $\frac{c}{d}$ represent ratios, say the ratios of the number of a student's correct answers in tests 1 and 2 over the number of questions in each test ( $\frac{a}{b}$ and $\frac{c}{d}$, respectively). The fact that $\frac{a}{b}$ is 
smaller than $\frac{c}{d}$ implies that the ratio of the number of correct answers over the number of questions in test 2 was bigger than the corresponding ratio in test 1. After applying reasoning similar to the one in the context of the "distance-time" graph here, one can conclude that the ratio of the total number of the student's correct answers in the two tests over the total number of questions in the two tests (i.e., $\frac{a+c}{b+d}$ ) has to be bigger than the ratio in test 1 (i.e., $\frac{a}{b}$ ) and smaller than the ratio in test 2 (i.e., $\frac{c}{d}$ ).

Second, it is hard to describe precisely the pedagogical context of a P-R mathematics task: given the complexities of any classroom situation, it is impractical (perhaps impossible) to describe all the parameters of the situation that can be relevant to the task's solution. This lack of specificity of the pedagogical context is potentially useful for university instructors implementing P-R mathematics tasks with their prospective teachers. Specifically, instructors can use the endemic ambiguity surrounding the conditions of a pedagogical context to vary some of its conditions in order to engage prospective teachers in related mathematical activities. Consider, for example, the pedagogical context of the Fractions Task, which does not specify whether the class would be able to produce an algebraic proof like the one in Figure 2. An instructor could exploit this ambiguity to engage prospective teachers in the development of other arguments that are likely to be more accessible to students, such as the arguments we discussed earlier. Each of these alternative arguments is based on different assumptions about the level of students' knowledge, and it is important to make this explicit in the proposed mathematical solutions to the task.

Third, the pedagogical context of a P-R mathematics task has the potential to motivate prospective teachers' engagement in the task by helping them see why the mathematical ideas in the task are, or can be, important for their future work as teachers of mathematics. According to Harel [14], "[s]tudents are most likely to learn when they see a need for what we intend to teach them, where by 'need' is meant intellectual need, as opposed to social or economic need" (p. 501; the excerpt in the original was in italics). In the case of prospective teachers, a "need" for learning mathematics may be defined in terms of developing mathematical knowledge that they need for teaching, i.e., knowledge of MfT. By helping prospective teachers see a need for the ideas they are being taught in mathematics courses for prospective teachers, it is more likely that they will get interested in learning these ideas. This is particularly important for mathematical ideas that prospective teachers tend to consider difficult or "advanced" for the level of the students they will be teaching, such as the notion of proof for pre-high school students.

Fourth, the design and implementation of P-R mathematics tasks require some pedagogical knowledge by instructors of mathematics courses for prospective teachers. For example, the design of the Fractions Task used knowledge about a common student misconception in the domain of proof and considered a possible link between this student misconception and a teacher's evaluation of, and response to, a novel student method. The pedagogical demands imposed by the design of P-R mathematics tasks on the instructors' knowledge can create challenges for those who may have limited background in pedagogy or familiarity with the school mathematics curriculum. Similar challenges could emerge also for instructors during the implementation of P-R mathematics tasks with prospective teachers, especially in relation to the question of what kinds of variations an instructor could make to the pedagogical context of a task without compromising the task's realistic nature. We return to these issues in the last section of the article.

\section{Exemplifying the Use of P-R Mathemat- ics Tasks in a Mathematics Course for Prospective Elementary Teachers}

This section is organized in two parts. In the first part we provide a brief description of major features of a mathematics course for prospective elementary teachers that we developed to promote MfT as a form of applied mathematics. Given the importance we attribute to P-R mathematics tasks in thinking about MfT as a form of applied mathematics, P-R mathematics tasks had a prominent place in the course. Yet P-R mathematics tasks were not the only kinds of tasks we used in the course. Another kind was what we call typical mathematics tasks, which embody only feature 1 of P-R mathematics tasks. Advantages of typical mathematics tasks are that they allow for a faster pace during university sessions than P-R mathematics tasks do and do not require any pedagogical knowledge from the instructor.

In the second part we illustrate the use of P-R mathematics tasks in the course by discussing the implementation of a task sequence, which includes both a typical and a P-R mathematics task. We developed this and other task sequences in a four-year study that used design experiment methodology [15]. The design experiment included five research cycles of implementation, analysis, and refinement of different task sequences in the course. In this article we discuss the implementation of one task sequence from the last research cycle of the design experiment. The last research cycle was conducted in two sections of the course 


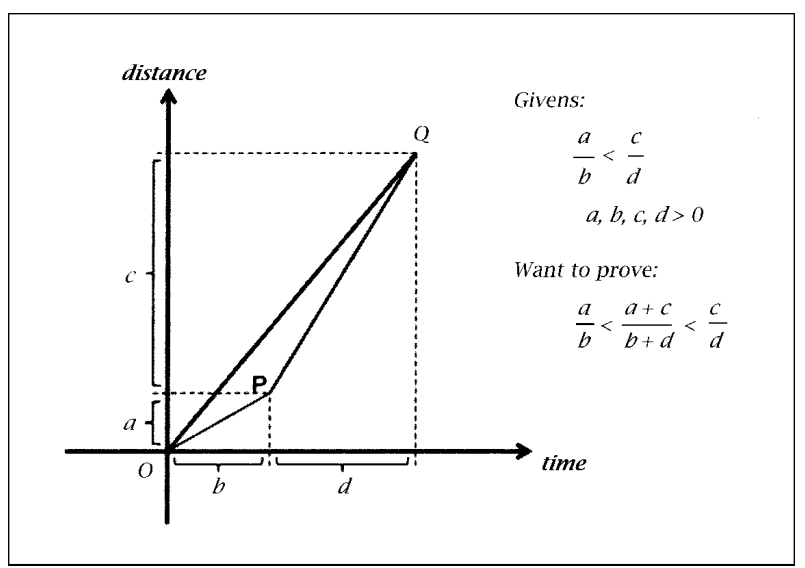

Figure 3. A distance-time graph that can be elaborated on in a potential proof of a general method for finding a fraction between two given positive and nonequivalent fractions.

with a total of thirty-nine prospective elementary teachers and the second author as the instructor. The data come from the implementation of the task sequence in one of the sections.

\section{General Description of the Course}

This three-credit undergraduate mathematics course was prerequisite for admission to the master's-level elementary teaching certification program at a large American state university. Contrary to what usually happens with mathematics courses for prospective elementary teachers in North America [16], the course was offered by the Department of Education rather than by the Department of Mathematics. Yet this did not make any difference to the fact that this was a mathematics course. ${ }^{3}$ The students in the course pursued undergraduate majors in different fields of study and tended to have weak mathematical backgrounds (for many of them this was the first mathematics course since high school). Also, given that the students were not yet in the teaching certification program, they had limited or no background in pedagogy.

The course was the only mathematics course specified in the admission requirements for the teaching certification program. It covered a wide range of mathematical topics in different mathematical domains (arithmetic, algebra, number theory, geometry, and measurement) and was intended to improve prospective teachers' understanding of key mathematical concepts and procedures in those topics. In addition to mathematical topics, the course emphasized the following three

\footnotetext{
${ }^{3}$ The first two research cycles of the design experiment took place at another large American state university where the course was offered through the mathematics department.
}

mathematical practices: (a) reasoning-and-proving (i.e., making mathematical generalizations and formulating arguments for or against these generalizations, with particular attention to the use of definitions), (b) problem solving, and (c) making connections between different forms of representation (algebraic, pictorial, etc.). With these three practices, which we treated as strands that underpinned prospective teachers' mathematical work, we aimed to also help prospective teachers appreciate what it means to "do" mathematics through engaging them with more authentic mathematical experiences, not merely helping them learn (or relearn) mathematical concepts and procedures.

One aspect of the course's approach to promote MfT, which is the most relevant to our purposes in this article (other features are discussed in [17] and [18]), was the use of both typical and P-R mathematics tasks in carefully designed task sequences. A common task sequence began with a typical mathematics task that set the stage for a P-R mathematics task. The typical mathematics task allowed prospective teachers to work on a mathematical idea from an adult's standpoint. The P-R mathematics task, which followed the typical task, introduced a pedagogical context that prospective teachers had to consider in their mathematical work, thus engaging prospective teachers in mathematical work from a teacher's standpoint. To address feature 2 of P-R mathematics tasks concerning situating prospective teachers' mathematical work in a pedagogical context, we used a wide range of classroom scenarios based on actual classroom records: videos or written descriptions of classroom episodes in elementary classrooms, artifacts of elementary students' mathematical work, excerpts from elementary mathematics textbooks, etc. When actual classroom records were unavailable, we used fictional records that were nevertheless realistic.

\section{An Example of a Task Sequence and Its Implementation in the Course}

The task sequence aimed to promote prospective teachers' knowledge about a possible relation between the notions of area and perimeter of rectangles. Central to this exploration were also ideas of mathematical generalization and proof by counterexample. The sequence included a typical mathematics task (question 1) followed by a P-R mathematics task (question 2):

Imagine that one of your students comes to class very excited. She tells you that she has figured out a theory that you never told the class. She explains that she has discovered that as the perimeter of a rectangle increases, the area also increases. 
She shows you the work in Figure 4 below to prove what she is doing:
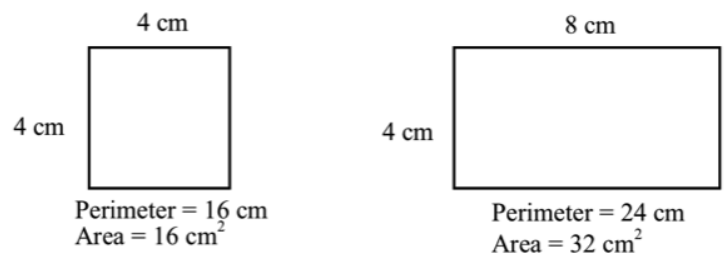

Figure 4.

1. Evaluate mathematically the student statement (underlined).

2. How would you respond to this student?

The task sequence was an adaptation of tasks that were originally developed by Ball [19] and subsequently used by Ma [2].

Although question 1 refers to a student statement, it is a typical mathematics task, because the prompt asks prospective teachers to mathematically evaluate the statement without asking or expecting them to take into account the fact that the statement was produced by a student. Question 2, on the other hand, is a P-R mathematics task, because it introduces a pedagogical consideration that prospective teachers need to take into account in their mathematical work. Although not explicitly mentioned in the task, it was understood in the teacher education class that answers to prompts like the one in question 2 should not focus on pedagogical issues (e.g., "I'd teach again the notion of perimeter and area..."), but should rather focus on the underlying mathematical issues by appropriately considering the relevant pedagogical context.

The mathematical focus of this P-R mathematics task is to evaluate mathematically the underlined statement, which is essentially what the prospective teachers were asked to do in question 1. The pedagogical context of the task concerns the teacher's responsibility to respond to the student who produced the statement. An appropriate response to question 1 could say that the statement is false and provide a counterexample to refute it. However, an appropriate response to question 2 would need to go beyond that. Consideration also of the pedagogical context suggests that it would be useful for the student's learning if the teacher not only refuted the student's statement (by providing a counterexample) but also helped her understand why the statement is false and explore the conditions under which the statement would be true. This additional work, though pedagogically situated, is deeply mathematical in nature and is the kind of work that we argue deserves more attention in mathematics courses for prospective teachers.

The prospective teachers worked on the two questions first individually and then in groups of four or five. Later on there was a wholeclass discussion, which began with the instructor (Stylianides) asking representatives from different small groups to report their work on the task, beginning with question 1 (all prospective teacher names are pseudonyms).

Andria: $\quad$ We [the members of her small group] said that it [the student statement] was mathematically sound, because as you increase the size of the figure, the area is going to increase as well.

Tiffany: We [the members of her small group] agreed. We thought the same, because as the sides are getting bigger...[inaudible]

Stylianides: Does anybody disagree? [No group expressed a disagreement.]

Evans: $\quad$ I agree. [Evans was in a different small group than Andria and Tiffany.]

Stylianides: And how would you respond to the student?

Melissa: I think it's true, but they haven't proved it for all numbers, so it's not really a proof.

Andria: $\quad$ I think that you don't have to try every number [she seems to refer to every possible case in the domain of the statement] to be able to prove it, because if the student can explain why it works like we just did, like if you increase the length, then the area increases. [pause] [...]

Meredith: I'd say that it's an interesting idea, and I'd see if they can explain why it works.

As illustrated by the above transcript, all small groups thought that the student statement was true, but at the same time they seemed to realize that the evidence that the student provided for her claim was not a proof (see, e.g., Melissa's comment). As a result, the prospective teachers started to think about how to prove the statement and how to respond to the student. For example, Andria and Meredith pointed out that the student needed to prove/explain why the area of a rectangle increases as its perimeter increases, with Andria appearing to believe that she already had a proof. However, the instructor knew that the statement was false. As the representative of the mathematical community in the classroom, he probed the prospective teachers to check more cases to see whether they could come up with an example in which the student 
statement was false. After a few minutes, all small groups found at least one counterexample to the statement and concluded that the statement was false. We note that earlier in the course the prospective teachers had opportunities to discuss the idea that one counterexample suffices to refute a general mathematical statement.

The prospective teachers' counterexamples to the student statement made them experience a "cognitive conflict", because at the initial stages of their engagement with the task sequence, they did not expect that a statement that looked so "obvious" to them would turn out to be false. This unexpected discovery motivated prospective teachers' further work on question 2. The instructor decided to give the prospective teachers more time to think in their small groups about question 2 . The transcript below is from the whole-class discussion that followed the small-group work.

Natasha: We said that the way that they [the students] are doing it, where they're just increasing the length of one side, it's always going to work for them; but if they try examples where they change the length on both sides, that's the only way it's going to prove that it doesn't work all the time. So you should try examples by changing both sides.

Stylianides: [referring to the class] What do you think about Natasha's response? Does it make sense? [The class nods in agreement.] So what else? What else do you think about this?

Evans: $\quad$ You can kind of ask them to restructure the proof so that it would work.

Stylianides: What do you mean by "restructure the proof"?

Evans: Like once they figure out that it doesn't work for all cases, they could say it's still like... if they saw it and if they revise it like the wording or just add a statement in there that if they can come up with a mathematically correct statement...

Stylianides: Anything else? [No response from the class.] I think both ideas [mentioned earlier] are really important. So when you have something [a statement] that doesn't work, then it's clear that this student would be interested to know more. For example, why it doesn't work or under what conditions does it work, because, obviously, some of the examples that the student checked worked. ...
Natasha and Evans raised two related issues that the teacher in the scenario of the P-R mathematics task could address when responding to the student: (a) why the statement is false (instead of simply showing that the statement is false with a counterexample) and (b) the conditions under which the statement would be true. Based on our planning for the implementation of the task, the instructor would raise these issues anyway, because, as we explained earlier, we considered it mathematically sufficient but pedagogically inconsiderate for a teacher to offer only a counterexample to the student's statement. We considered such a response inadequate in light of the pedagogical context of the task.

It is noteworthy that the two issues were raised not by the instructor but by two prospective teachers, Natasha and Evans, who (like the other prospective teachers in the class) had no teaching experience. It is difficult to say what provoked the contributions of these prospective teachers, but we speculate that the pedagogical context of the $\mathrm{P}-\mathrm{R}$ mathematics task played a role in this. It is also possible that the P-R mathematics tasks we used earlier in the course had helped the prospective teachers begin to develop pedagogical sensibilities.

Following a summary of the two issues in Evans's contribution, the instructor engaged the prospective teachers in an examination of the conditions under which the student statement would be true. Specifically, he asked the prospective teachers to investigate what happens to the area of a rectangle in each of the following cases where the perimeter of the rectangle increases:

1. One of the two dimensions (length or width) is increased and the other dimension is kept constant.

2. Both dimensions are increased.

3. One of the two dimensions is increased and the other dimension is decreased, so that the amount of increase in one dimension is larger than the amount of decrease in the other.

The prospective teachers produced algebraic and pictorial proofs to show that in the first two cases the area always increases and examples to show that in the third case the area can increase, decrease, or stay the same.

To conclude, our discussion of the implementation of the task sequence exemplified the idea that the application of mathematical knowledge in pedagogical contexts can be different from its application in similar but purely mathematical contexts. Although the typical mathematics task and the P-R mathematics task in the sequence were dealing with the same mathematical ideas, the pedagogical context in which the P-R mathematics 
task was embedded shaped what could count as an appropriate mathematical solution to it, thereby supporting the generation of rich mathematical activity in a realistic pedagogical context.

\section{Concluding Remarks}

The design, implementation, and solution of P-R mathematics tasks suggest that instructors of university mathematics courses for prospective teachers who may want to use these tasks in their courses need to have not only good mathematical knowledge but also some knowledge of schoolrelated pedagogy (including familiarity with the school mathematics curriculum). For example: What arguments for a true generalization could be accessible to students of different ages? In addition to offering a counterexample, what other mathematical investigations would be pertinent in a pedagogical context where a student proposed a false generalization?

In countries such as the United States where mathematics courses for prospective teachers are typically offered by mathematics departments [16], it may be unrealistic to require or expect that instructors of these courses have good knowledge of pedagogy in addition to their robust mathematical knowledge [20]. However, if certain knowledge of pedagogy is recognized to be useful for teaching MfT to prospective teachers, ways need to be found to support these instructors in their work.

One way could be through textbooks intended for use in mathematics courses for prospective teachers. Textbooks that would be consistent with the conceptualization of MfT as a form of applied mathematics discussed in this article would not only include P-R mathematics tasks (alongside typical and possibly other kinds of mathematics tasks) but would also include the following: (a) the rationale for the design of P-R mathematics tasks and associated target learning goals for prospective teachers, (b) suggestions for implementing the tasks with prospective teachers, and (c) comments about how the tasks relate to school mathematics (e.g., an elaboration on the pedagogical context of the tasks and how this context can shape mathematical solutions).

To conclude, the conceptualization of MfT as a form of applied mathematics highlights the idea that prospective teachers' learning of MfT should not happen in isolation from the context in which teachers will need to apply this knowledge. P-R mathematics tasks can provide a vehicle through which prospective teachers' learning of mathematics can be connected to the teaching practice. On the one hand, these tasks have mathematics at the core of prospective teachers' activity; this is a necessity given that they are meant for use in mathematics courses. On the other hand, they situate this mathematical activity in a substantial pedagogical context that shapes and influences the activity, thereby ensuring that prospective teachers' learning of mathematics does not lose sight of its domain of application.

\section{References}

[1] G. J. StYlianides and A. J. STYLiAnides, Mathematics for teaching: A form of applied mathematics, Teaching and Teacher Education 26 (2010), pp. 161-172.

[2] L. MA, Knowing and Teaching Elementary Mathematics, Erlbaum, Mahwah, NJ, 1999.

[3] D. L. BALL and H. BASs, Interweaving content and pedagogy in teaching and learning to teach: Knowing and using mathematics, in Multiple Perspectives on Mathematics Teaching and Learning (J. Boaler, ed.), Ablex Publishing, Westport, CT, 2000, pp. 83-104.

[4] , Making mathematics reasonable in school, in A Research Companion to Principles and Standards for School Mathematics (J. Kilpatrick, W. G. Martin, and D. Schifter, eds.), National Council of Teachers of Mathematics, Reston, VA, 2003, pp. 27-44.

[5] M. Goulding, T. Rowland, and P. BARber, Does it matter? Primary teacher trainees' subject knowledge in mathematics, British Educational Research Journal 28 (5) (2002), pp. 689-704.

[6] W. G. MARTin and G. HARel, Proof frames of preservice elementary teachers, Journal for Research in Mathematics Education 20 (1989), pp. 41-51.

[7] G. HAREL and L. SOWDER, Toward comprehensive perspectives on the learning and teaching of proof, in Second Handbook of Research on Mathematics Teaching and Learning (F. K. Lester, ed.), Information Age Publishing, Greenwich, CT, 2007, pp. 805-842.

[8] A. J. STYlianides and D. L. BALL, Understanding and describing mathematical knowledge for teaching: Knowledge about proof for engaging students in the activity of proving, Journal of Mathematics Teacher Education 11 (2008), pp. 307-332.

[9] H. BASs, Mathematics, mathematicians, and mathematics education, Bulletin of the American Mathematical Society 42 (2005), pp. 417-430.

[10] H. WU, How mathematicians can contribute to K-12 mathematics education, Proceedings of the International Congress of Mathematicians, Madrid, 2006, Volume III, European Mathematical Society, Zürich, 2006, pp. 1676-1688.

[11] Z. Usiskin, Teachers' Mathematics: A Collection of Content Deserving To Be a Field, National Summit on the Mathematical Education of Teachers, 2001, (Retrieved January 6, 2012, from http://cbmsweb. org/Nationa1Summit/wg_speakers.htm.)

[12] Z. USISKIN, A. Peressini, E. A. MARChisotTo, and D. STANLEY, Mathematics for High School Teachers: An Advanced Perspective, Prentice Hall, Upper Saddle River, NJ, 2003.

[13] J. ADLER and Z. DAVIS, Opening another black box: Research mathematics for teaching in mathematics teacher education, Journal for Research in Mathematics Education 37 (2006), pp. 270-296.

[14] G. HAREL, Two dual assertions: The first on learning and the second on teaching (or vice versa), American Mathematical Monthly 105 (1998), pp. 497-507. 


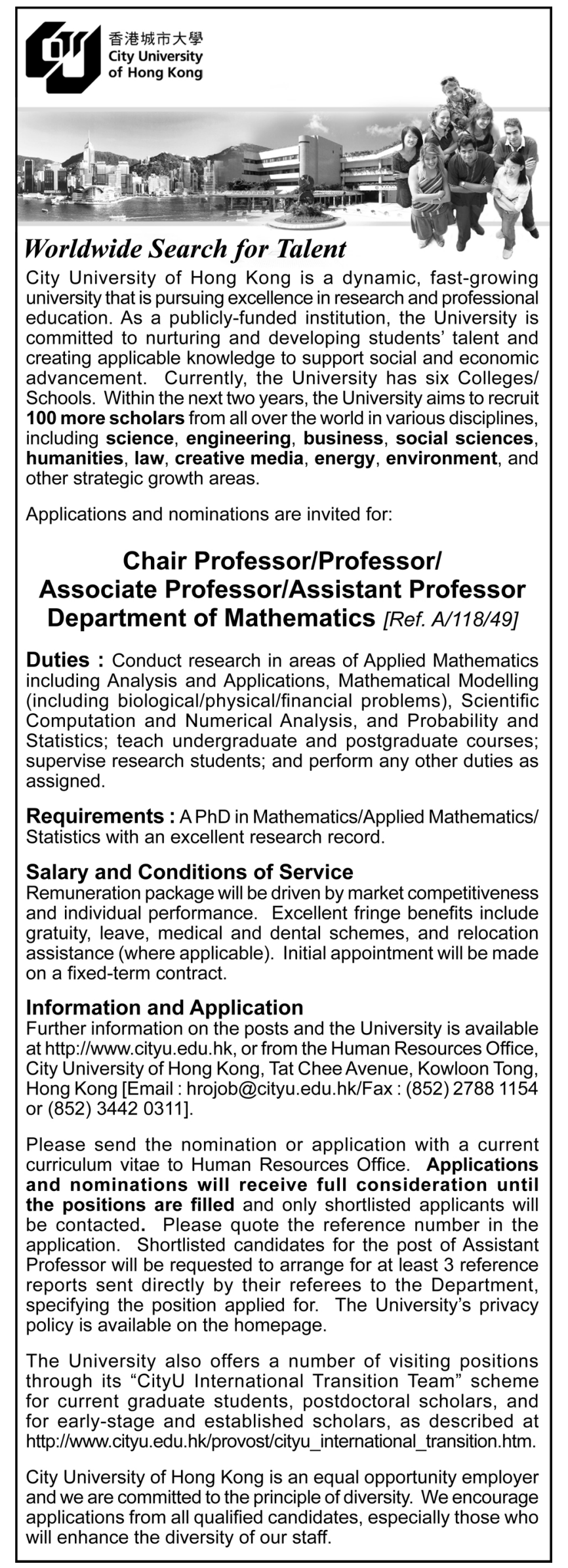

[15] P. Cobb, J. Confrey, A. Disessa, R. Lehrer, and L. SCHAUble, Design experiments in educational research, Educational Researcher 32 (1) (2003), pp. 9-13.

[16] B. DAVIS and E. SIMmT, Mathematics-for-teaching: An ongoing investigation of the mathematics that teachers (need to) know, Educational Studies in Mathematics 61 (2006), pp. 293-319.

[17] G. J. STYliAnides and A. J. STYLIANIDES, Facilitating the transition from empirical arguments to proof, Journal for Research in Mathematics Education 40 (2009), pp. 314-352.

[18] A. J. Stylianides and G. J. StYlianides, Impacting positively on students' mathematical problem solving beliefs: An instructional intervention of short duration, Journal of Mathematical Behavior 33 (2014), pp. 8-29.

[19] D. L. BALL, Knowledge and reasoning in mathematical pedagogy: Examining what prospective teachers bring to teacher education, unpublished doctoral dissertation, Michigan State University, East Lansing, MI, 1988.

[20] J. O. MASINGILA, D. E. OLANOFF, and D. K. KWAKA, Who teaches mathematics content courses for prospective elementary teachers in the United States? Results of a national survey, Journal of Mathematics Teacher Education 15 (2012), pp. 347-358. 